\title{
Editorial A Farewell to Arms
}

It has been six years since I took over the reins of JPET editorship from Mike Jarvis, and in January of 2022, I will pass on the role to the very capable hands of Beverley Greenwood-Van Meerveld. It has been my pleasure and honor to serve ASPET members in continuation of John J. Abel's 1908 Baltimore meeting, where the decision was reached to start a pharmacology society and subsequently, a year later, JPET as a means to disseminate scholarly pharmacology information. The first JPET volume (1909-1910) contained 24 papers, approximating the content of some monthly issues today. This reflects the growth of ASPET and the journal's appeal to nonmembers, who contribute significantly to its content. Interestingly, while early ASPET members were mandated to have affiliations with academic centers, JPET now has a vital attachment to scientists from the pharmaceutical industry, and many choose JPET as a publication venue. Any particular JPET issue will have representative publications from all of these sectors.

What challenges await my successor? Pharmacology as a discipline is changing, and in recent times, students and postdocs in pharmacology frequently establish themselves with hybrid expertise. Pharmacology departments now have many faculty members who are trained in molecular and biochemical aspects of the discipline. The pharmaceutical industry and biotechnology companies provide a large share of the drug discovery and development initiatives, and strong participation and representation from each sector will continue to be advantageous. ASPET meetings (pandemic notwithstanding) are destined to separate from other FASEB societies, and maintaining a critical mass of meeting participants and journal authors will be important. Establishing and maintaining a strong connection with Asia will also reflect the increased interest and submissions originating from this region. Perhaps because JPET is a society-based journal, the "impact factor" has not altered dramatically since its inception. Continued commitment from ASPET members to JPET and our other society journals could help to enhance this value.

Academic publishing has undergone significant evolution over the past six years. We now have software that checks image authenticity and plagiarism, and we recently have accommodated open access into the business model for the journal. In each of these stages of journal development, I have been fortunate to have had a steady group of talented associate editors and a committed collection of editorial board members who have helped to advance initiatives. Moreover, staff members at the ASPET office in Rockville have served the journal tirelessly. Recently, the indefatigable Rich Dodenhoff retired and was replaced by Maria Pasho; Jackie Perry and Cassie Wood have consistently made the review and publication processes seamless. I am indebted to each and every one of them. ASPET Publications Committee members have also had an integral role in journal quality control and evolution; while not wishing to provide a lengthy list, I would like to extend thanks to Mary Vore and, more recently, Emily Scott for their leadership roles. In closing, I would like to extend my thanks to all the many contributors to JPET. I wish Beverley all the best and hope she enjoys the role as much as I have.

Kenneth D. Tew Editor 